\title{
Connecting river to sea by a 2-D mathematical model
}

\author{
A. Astaraki \& F. Fallah \\ Civil Engineering Department, Islamic Azad University, Iran
}

\begin{abstract}
A two dimensional mathematical model is presented to simulate flow and suspended sediment transport in rivers. A two dimensional horizontal depth average model computes the flow characteristics. The hydrodynamic model uses a fully implicit finite difference numerical scheme with variable grid size. By solving the equation of sediment transport, the sediment concentration will be calculated. The depth variations could be computed by solving continuity equation of sediment. In this Paper, verification of the model and ability of Model in the field of connecting a river to the sea is shown by figures.
\end{abstract}

Keywords: mathematical modeling, suspended sediment transport, sea, river.

\section{Introduction}

In recent decades a lot of numerical and physical models have been developed in the field of river engineering. Physical models are generally very timeconsuming, costly and for many practical problems, impossible, while mathematical models are becoming more popular because of low cost, flexibility in design for changing different plans, ability to simulate riverbed deformation under large scale and long term conditions and they also provide a large quantity of information.

However any mathematical model is faced with some problems, for example using concept of equilibrium sediment transport is an important problem in mathematical models. In this model a 2-D mathematical model of flow and suspended sediment transport has been developed for alluvial rivers in which concept of nonequilibrium sediment transport is used. In the concept of equilibrium suspended sediment transport, sediment transport capacity is supposed to be equal with sediment concentration while alluvial rivers are 
always under nonequilibrium conditions because of the variable inflow, various human activities such as reservoir construction and water diversion, and etc. [1]. Charafi et al. [2] presented a quasi 3-D mathematical model of morphological processes and based on his model mentioned it is not recommended to apply an equilibrium transport formula to compute morphological variations.

Celic and Rodi [3] propounded none of empirical formula does not have universal value because it is impossible to determine boundary between bed load and suspended load, so this model doesn't use the empirical formulas to estimate suspended sediment transport, in fact in this model, the difficulties in most before models like using practical formulas and determining concentrations of bed load has been omitted by using a new algorithm.

\section{Equations}

\subsection{Flow equations}

$$
\begin{gathered}
\frac{\partial q_{x}}{\partial x}+\frac{\partial q_{y}}{\partial y}+\frac{\partial \eta}{\partial t}=0 \\
\frac{\partial q_{x}}{\partial t}=-\frac{\partial q_{x} q_{y} / d}{\partial y}-\frac{\partial q_{x}^{2} / d}{\partial x}-\frac{d}{\rho} \frac{\partial p}{\partial x}-g d \frac{\partial \eta}{\partial x}+\frac{d}{\rho} \frac{\partial \tau_{1}}{\partial y}+\frac{1}{\rho}\left(\tau_{x s}-\tau_{x b}\right)+f q_{y} \\
\frac{\partial q_{y}}{\partial t}=-\frac{\partial q_{x} q_{y} / d}{\partial x}-\frac{\partial q_{y}^{2} / d}{\partial y}-\frac{d}{\rho} \frac{\partial p}{\partial y}-g d \frac{\partial \eta}{\partial y}+\frac{d}{\rho} \frac{\partial \tau_{1}}{\partial x}+\frac{1}{\rho}\left(\tau_{y s}-\tau_{y b}\right)-f q_{x}
\end{gathered}
$$

where $q_{x}$ and $q_{y}$ are water discharge component in the $\mathrm{x}$ and $\mathrm{y}$ direction, respectively, $d=h+\eta$ is the total water depth, $h$ is the still water depth, $\eta$ is the fluctuation of water surface elevation, $p$ is the atmospheric pressure, $\rho$ is the density of water, $\mathrm{t}$ is time, $\mathrm{g}$ is gravity, $f=2 \Omega \sin \phi, \Omega$ is the angular speed of earth rotation, $\phi$ is the latitude of study site, $\tau$ is the shear stress [4].

\subsection{Unsteady nonequilibrium sediment transport equation}

$$
\frac{\partial h s}{\partial t}+\frac{\partial h u s}{\partial x}+\frac{\partial h v s}{\partial y}-\varepsilon_{s} \frac{\partial^{2}(h s)}{\partial x^{2}}-\varepsilon_{s} \frac{\partial^{2}(h s)}{\partial y^{2}}=-\alpha \omega\left(s-s^{*}\right)
$$

\subsection{Continuity equation of sediment}

$$
\rho^{\prime} \frac{\partial z}{\partial t}=\alpha \omega\left(s-\mathrm{s}^{*}\right)
$$


where $S$ is suspended sediment concentration, $S^{*}$ is sediment transport capacity, $\alpha$ is adjust coefficient, $\varepsilon_{s}$ is diffusion coefficient for sediment, u, v are depth averaged velocity in direction $\mathrm{x}$ and $\mathrm{y}[1]$.

\subsection{Solving equations}

A two dimensional horizontal depth average model computes the flow characteristics. The hydrodynamic model uses a fully implicit finite difference numerical scheme with variable grid size. A program developed in FORTRAN programming language solves the uncouple equation of sediment and current [5].

\section{Model verification}

In this paper, a comparison has been made between results of this model and a quasi 3-D model of Charafi et al. [2]. Solving network consist of a triangular channel with size of $100 * 3100$ meters and a horizontal bed and a dam $(100 * 400$ meters). Other main information is given below:

Intel discharge $=4000 \mathrm{~m}^{3} / \mathrm{s}$

Water depth in channel $=6 \mathrm{~m}$

$\rho_{s}=2650 \mathrm{~kg} / \mathrm{m}^{3}$

$D_{s}=200 \mu m$

Grid size in this model is variable 125 meter in x-direction and 50 meter in $\mathrm{y}$ direction which near dam location is smaller. In chart 1 and figure1, 2 results and comparison between this model and the Charafi et al. model have been shown.

Table 1: Computed flow velocity, water depth and concentration in different zones of Charafi et al. work [2] and present work.

\begin{tabular}{|c|c|c|c|c|c|c|c|}
\hline \multicolumn{2}{|c|}{$\begin{array}{c}\text { Point } \\
\text { coordinate }(\mathrm{m})\end{array}$} & \multicolumn{2}{c|}{$\begin{array}{c}\text { Current Velocity } \\
(\mathrm{m} / \mathrm{s})\end{array}$} & \multicolumn{2}{c|}{ Depth (m) } & \multicolumn{2}{c|}{$\begin{array}{c}\text { Sediment } \\
\text { Concentration } \\
(\mathrm{Kg} / \mathrm{m} 3)\end{array}$} \\
\hline $\mathrm{x}$ & $\mathrm{y}$ & Charafi & $\begin{array}{c}\text { Present } \\
\text { Work }\end{array}$ & Charafi & $\begin{array}{c}\text { Present } \\
\text { Work }\end{array}$ & Charafi & $\begin{array}{c}\text { Present } \\
\text { Work }\end{array}$ \\
\hline 1480 & 500 & 1.1 & 1.08 & 6.13 & 5.99 & 0.14 & 0.10 \\
\hline 1520 & 660 & 1.35 & 1.1 & 6.06 & 6.004 & 1.2 & 0.27 \\
\hline 1560 & 620 & 1.71 & 0.73 & 5.98 & 6.002 & 3.2 & 0.12 \\
\hline 1680 & 540 & 1.37 & 0.97 & 6.06 & 6.004 & 0.361 & 0.182 \\
\hline 160 & 820 & .65 & 0.60 & 6.24 & 5.91 & 0.123 & 0.106 \\
\hline 2320 & 580 & .84 & .88 & 6.02 & 6.002 & 0.098 & 0.074 \\
\hline
\end{tabular}




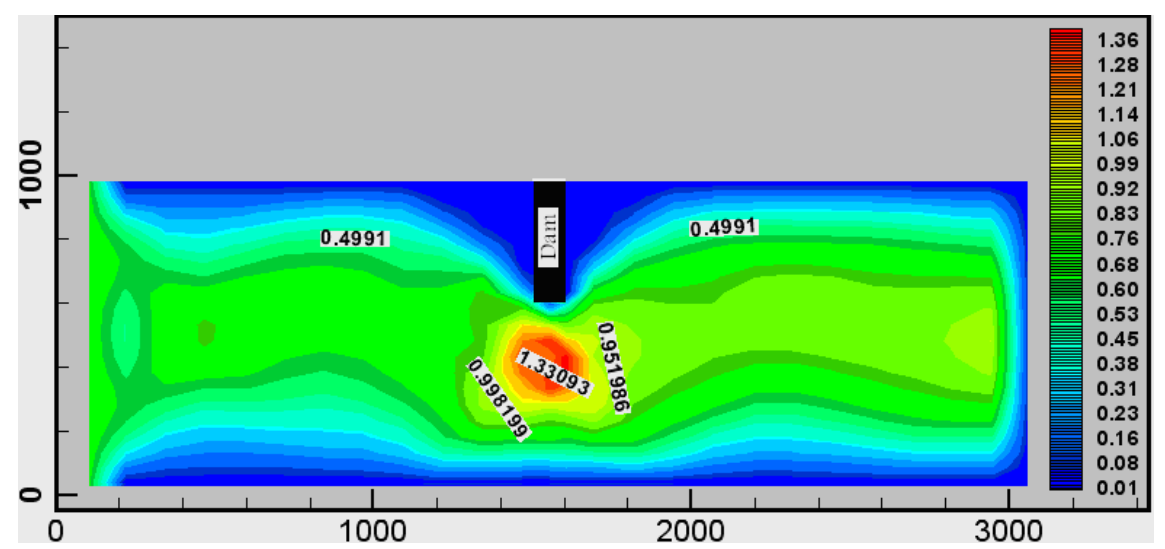

Figure 1: $\quad$ Computed flow velocity (present work).

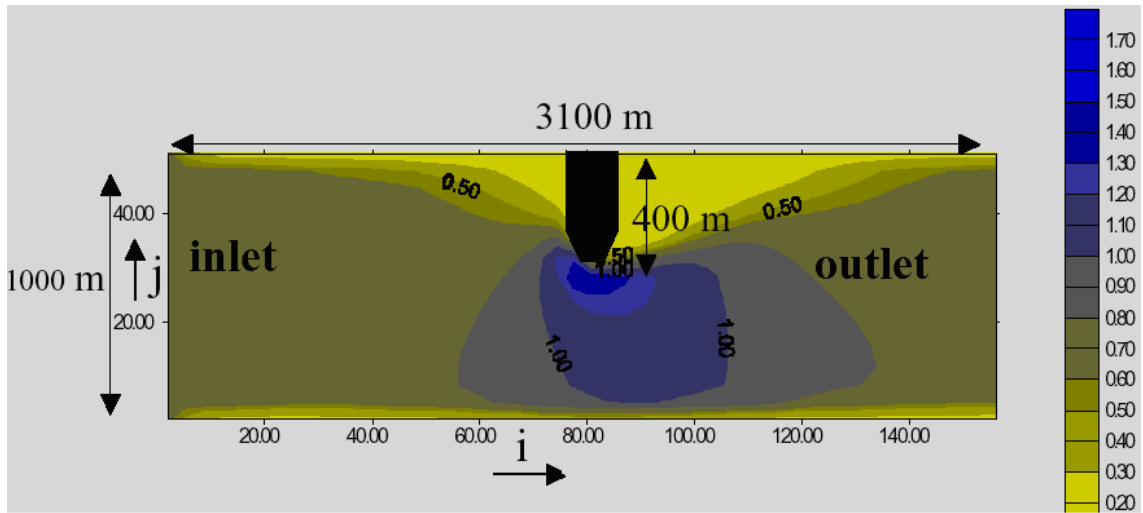

Figure 2: $\quad$ Computed flow velocity (Charafi et al. work) [2].

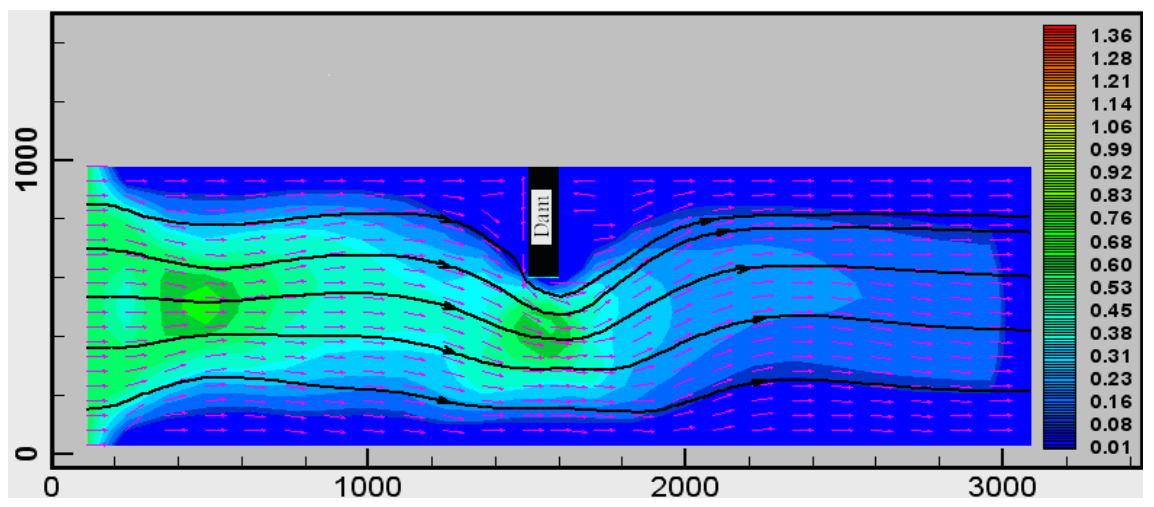

Figure 3: Ability of model in simulation of velocity vectors and flow lines (present work). 


\section{Simulation of river connection to sea}

In this part, ability of model in simulation connecting a river to the sea is shown by figures 5,6 and 7. Boundary conditions are shown in figure 4 and other characteristics of model is mentioned below. Results of the model in simulation of river connection to the sea are shown in figures 5-8.

Water level $=4 \mathrm{~m}$

River Discharge $=10 \mathrm{~m} 3 / \mathrm{ms}$

Constant water level in outlet (Sea water level) $=5 \mathrm{~m}$

Bed Slope $=0.0$

Sediment Particle Diameter $=200 \mu \mathrm{m}$.

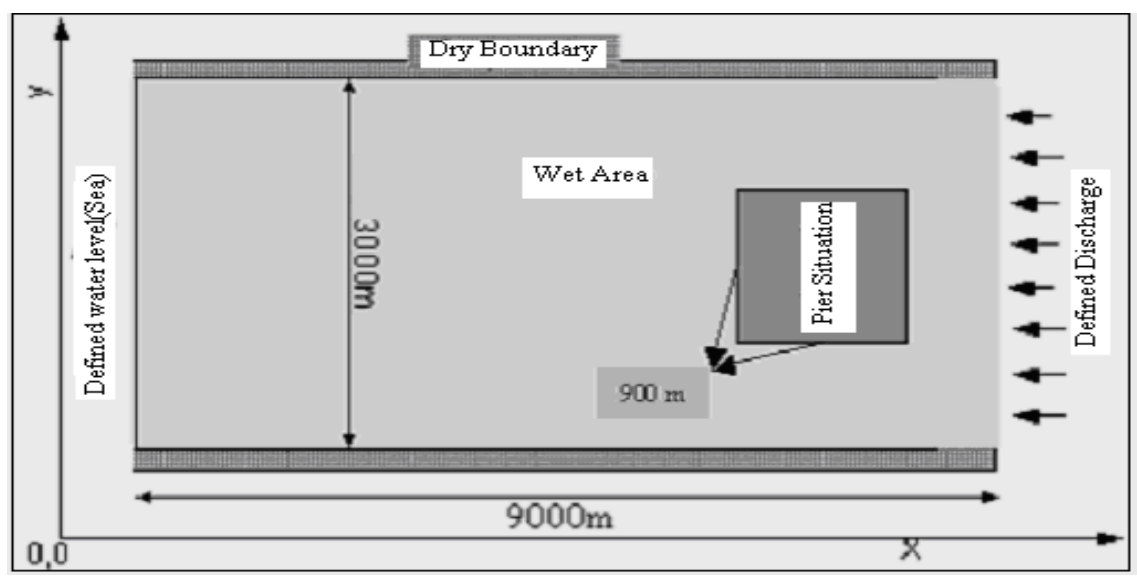

Figure 4: Conditions and details of simulation connecting river to sea.

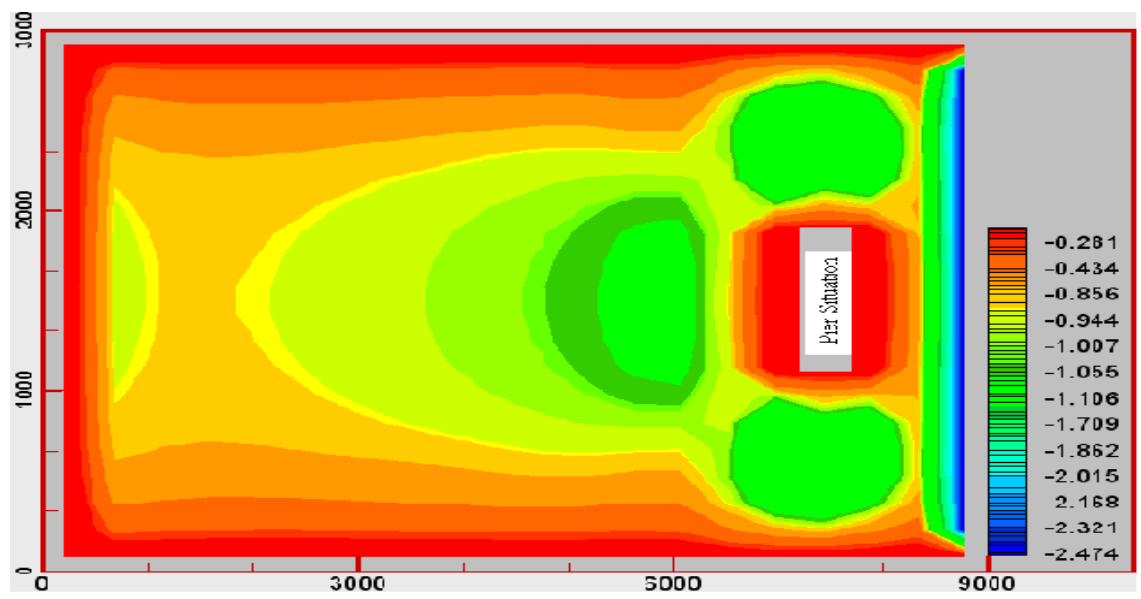

Figure 5: Variation of water velocity in $\mathrm{X}$ direction after 75 minutes $(\mathrm{m} / \mathrm{s})$. 


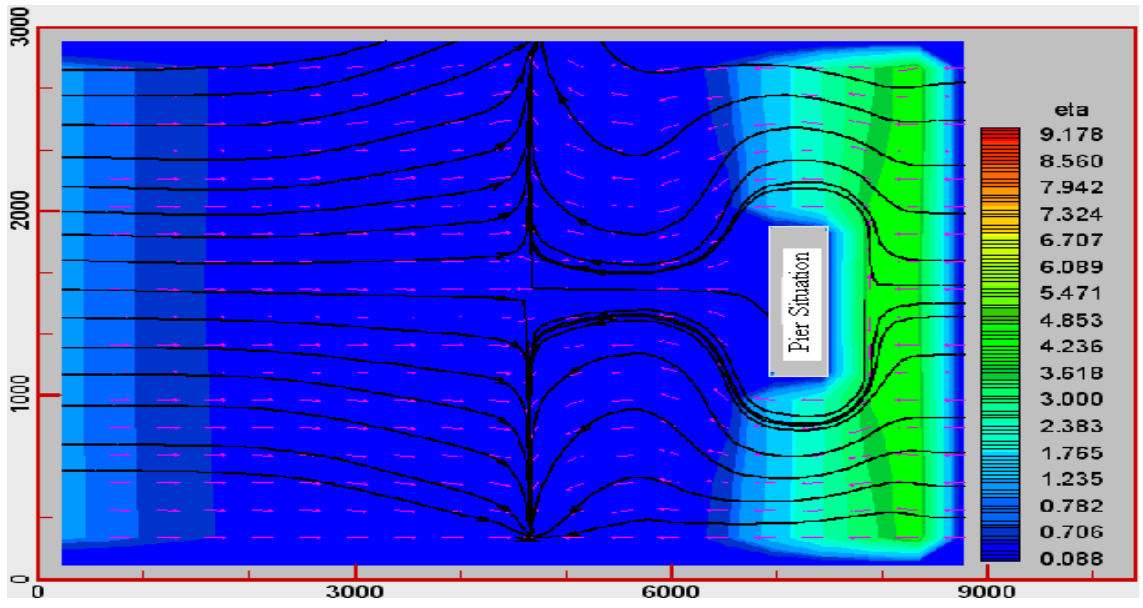

Figure 6: Variation of water level and velocity vectors and flow lines after 9 minutes.

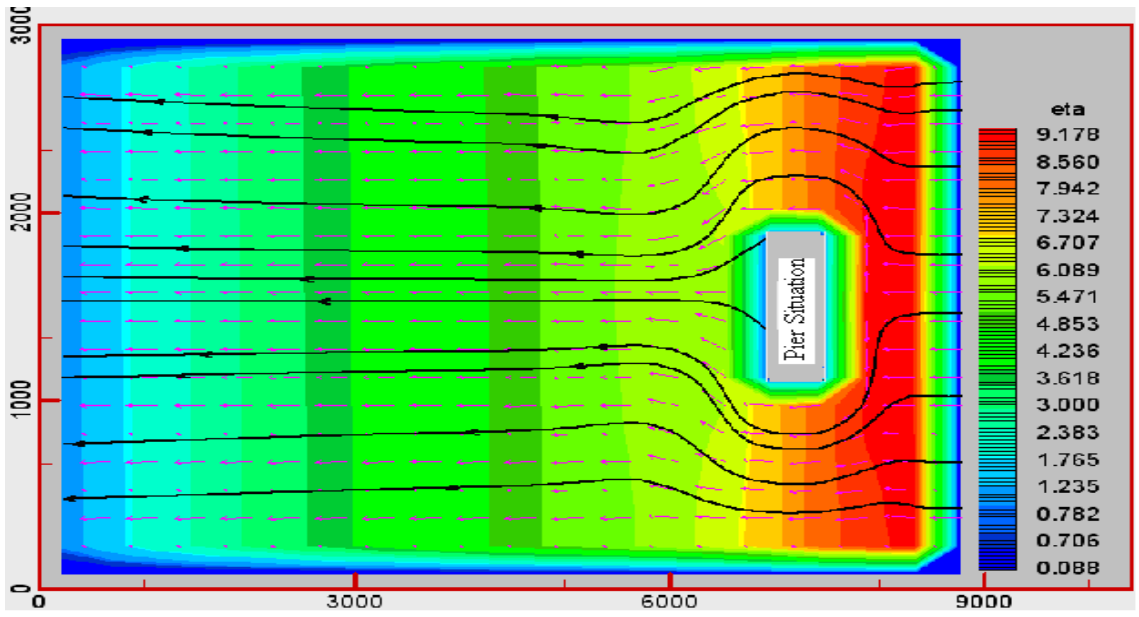

Figure 7: Variation of water level and velocity vectors and flow lines after 75 minutes.

\section{Conclusion}

In this research, a 2-D mathematical model of depth averaged in shallow water flows have been developed for processes of sediment transport in alluvial rivers. Hydrodynamic model uses a full implicit time-splitting numerical scheme with variable grid size. The sediment transport model uses a simple algorithm that both the difficulty of determining the reference concentration and problem of 


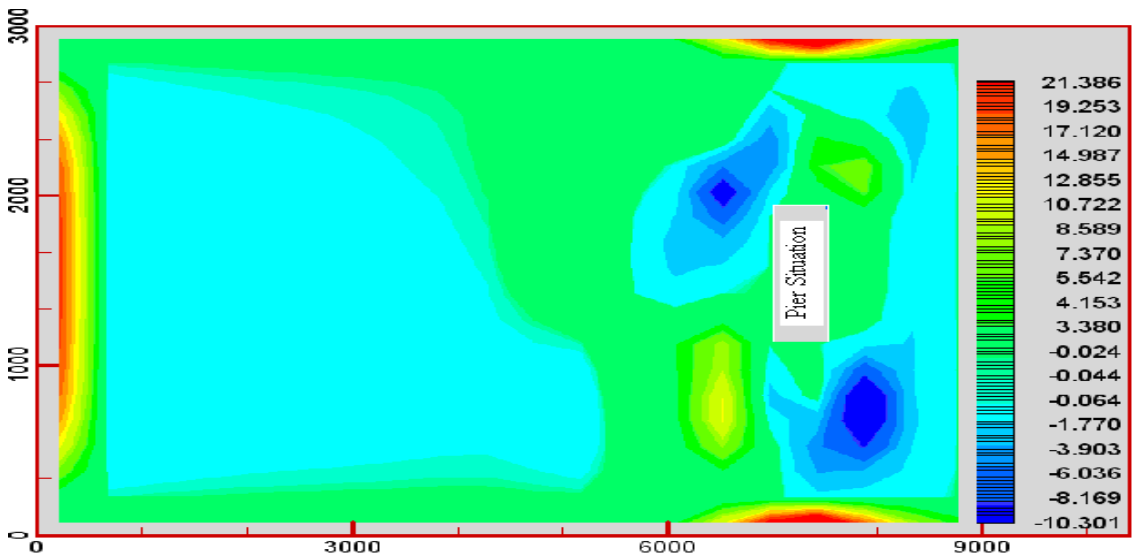

Figure 8: $\quad$ Total variation of bed after 75 minutes $(\mathrm{cm})$.

selecting the sediment transport function are avoided. Results of model are compared with the Charafi et al. model. In this comparison, flow velocities are near to the Charafi et al. model and maximum variation of water depth in two models is $6 \%$. Sediment concentrations in front of dam in two models show large amounts in accordance with other points which is obtained from rectangular elements. Also, ability of the model in simulation of connecting sea to river and total variation of river bed and variation of velocity in directions $\mathrm{x}$ and $\mathrm{y}$ has been shown by figures.

\section{References}

[1] Guo, Q. C., and Jin, Y. C. "Modeling Nonuniform Suspended Sediment Transport in Alluvial Rivers.", Journal of Hydraulic Engineering, ASCE, Vol. 128, No. 9, 2002.

[2] Charafi, My. M. and Sadok, A. and Kamal, A. and Menal, A., "Quasi-Three Dimensional Mathematic Modeling of Morphological Processes Based on Equilibrium Sediment Transport.", International Journal of Modern Physics C, Vol. 11, No. 7., 2000.

[3] Celik, I. and Rodi, W. "Modeling Suspended Sediment Transport in Nonequilibrium Situations.", J. Hydr. Engrg., ASCE, Vol. 114, No. 10, 1988.

[4] Jerome P.-Y. Maa, “An Efficient Horizontal Two-Dimensional Hydrodynamic Model.”, Journal of Coastal Engineering, No. 14, 1990.

[5] Astaraki, A., "Two Dimensional Mathematical Modeling of Flow and Sediment Transport in River.", Master of Science Thesis, Civil Department, Shahid Bahonar University of Kerman, Kerman, Iran, 2004. 